NASA Technical Memorandum 100951

AIAA-88-2821

NASA-TM-100951

19880015424

\title{
Characterization of Aluminum/RP-1 Gel Propellant Properties
}

Douglas C. Rapp

Sverdrup Technology, Inc.

NASA Lewis Research Center Group

Cleveland, Ohio

and

Robert L. Zurawski

National Aeronautics and Space Administration

Lewis Research Center

Cleveland, Ohio

Prepared for the

24th Joint Propulsion Conference

cosponsored by the AIAA, ASME, SAE, and ASEE

Boston, Massachusetts, July 11-13, 1988

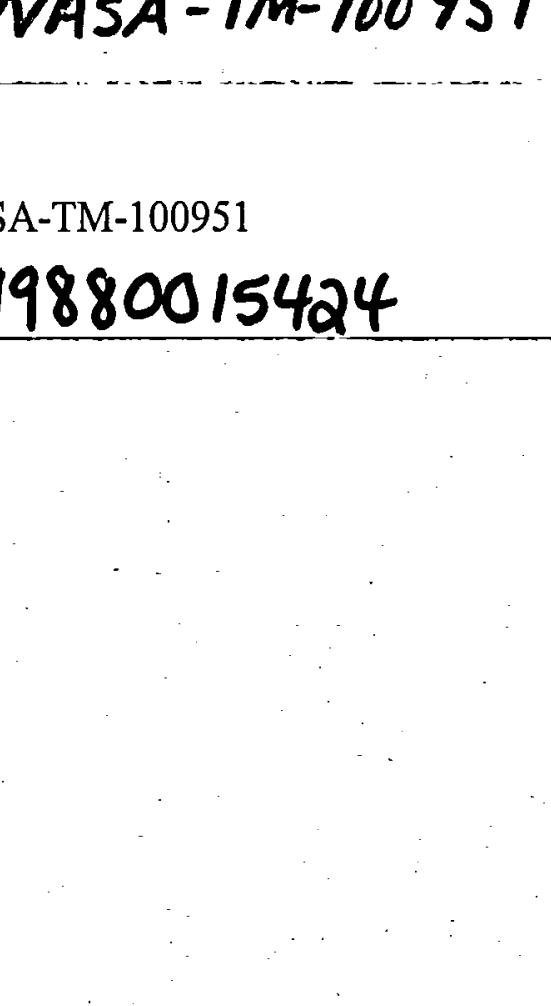

-

OCT 181988

LANGLEY RESEARCH CENTER HAMPPON, VIKGINIA

\section{N/SA}




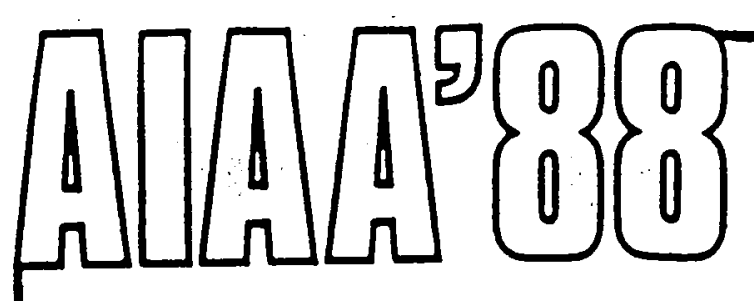
AIAA-88-2821
Characterization of Aluminum/RP-1
Gel Propellant Properties
Douglas C. Rapp, Sverdrup Technology,
Inc., NASA Lewis Research Center
Group, Cleveland, $\mathrm{OH}$; and Robert L.
Zurawski, NASA Lewis Research Center,
Cleveland, $\mathrm{OH}$

\section{AIAA/ASME/SAE/ASEE 24th JOINT PROPULSION CONFERENCE JULY 11-13, 1988/Boston, Massachusetts}


CHARACTERIZATION OF ALUMINUM/RP-1 GEL PROPELLANT PROPERTIES

\author{
Douglas C. Rapp \\ Sverdrup Technology, Inc. \\ NASA Lewis Research Center Group \\ Cleveland, Ohio 44135 \\ and \\ Robert L. Zurawski \\ National Aeronautics and Space Administration \\ Lewis Research Center \\ Cleveland, Ohio 44135
}

\begin{abstract}
SUMMARY
Research efforts are being conducted by the NASA Lewis Research Center to formulate and characterize the properties of AT/RP-1 and RP-1 gelled propellants for rocket propulsion systems. Twenty four different compositions of gelled fuels have been formulated with 5 and $16 \mu \mathrm{m}$, atomized aluminum powder in RP-1. The total solids concentration in the propellant varied from 5 to $60 \mathrm{wt} \%$. Tests were conducted to evaluate the stability and rheological characteristics of the fuels. Physical separation of the solids occurred in fuels with less than 50 wt \% solids concentration. The rheological characteristics of the Al/RP-l fuels varied with solids concentration. Both thixotropic and rheopectic gel behavior were observed. The unmetallized RP-1 gels, which were formulated by a different technique than the Al/RP-1 gels, were highly viscoelastic. A history of research efforts which have been conducted to formulate and characterize the properties of metallized propellants for various applications is also given.
\end{abstract}

\title{
INTRODUCTION
}

The addition of metals to liquid bipropellant systems has been investigated for a number of years because of the potential improvements in rocket propulsion system and vehicle performance. The specific impulse advantages derived from metallized propellants, such as Li/F2/H2, have been documented (ref. 1). However, recent evaluations of the concept for rocket propulsion applications have focused on the density-impulse relationship and delivered payload advantages. These studies have shown that metallized propellants offer substantial advantages compared to conventional liquid bipropellants in volume-limited propulsion system applications (ref. 2) and are promising propellants for rocket-powered single-stage-to-orbit vehicles and advanced booster propulsion systems. In addition, supplementing liquid propellants with a solid metallic phase often requires the gelation of the neat liquid carrier. The resultant semisolid state created by the gel addition provides a safety advantage with respect to tank rupture and spillage. This report summarizes recent efforts by the NASA Lewis Research Center to formulate, stabilize, and characterize the properties of aluminum/RP-l (Al/RP-1) fuels.

Metallized propellants consist of a solid, low molecular weight particulate metal or metallic compound in a liquid fuel or oxidizer. High density. 
low molecular weight and high combustion energy are desired properties of each propellant component. The metal or metallic compound is typically suspended in the neat liquid carrier for fluidic transport through the system tank, lines, manifold, and injector ports. These two-phase fluids may be slurries (small particulates, $\leq l \mu \mathrm{m}$ ), gels (larger particulates and a polymeric gellant additive), bimodal stábilized gels (large and small particulates and a polymeric gelliant additive) or emulsions (two immiscible liquids and an emulsifier) (ref. 3). Various preparation techniques and additives are used to formulate these propellants. Details of the preparation technique and stabllizing agents used for the Al/RP-1 geis reported herein are confidential due to similar work efforts by the U.S. Air Force. Therefore, some propellant compositions are reported with the additives generically coded.

A literature review of previous metallized propellant work reveals the relatively long history and range of applications of the metallized propellant concept. Early studies of metallized fuels conducted by the National Advisory Committee for Aeronautics (NACA) Lewis Research Center from 1947 to 1957 focused on aluminum, boron, and magnesium in hydrocarbon (JP) fuels to increase the thrust and flight range of ramjets. Aluminum was eliminated early in that program in favor of magnesium and boron. Deposition of sticky, molten aluminum oxide inside the combustor was a serious problem due to the relatively low combustion temperature in the ramjet. It was also learned that boron-slurry fuels were not satisfactory for use in afterburners or ramjet engines because of the poor combustion efficiency of fuels containing boron. Magnesium-slurry fuels performed successfully and could provide thrust greater than conventional liquid hydrocarbon fuels but could not increase the flight range of the ramjet (ref. 4).

Research on metallized fuels for propulsion systems subsequently focused on hypergolic propellant combinations, such as hydrazine and monomethylhydrazine with nitrogen tetroxide, IRFNA (inhibited red fuming nitric acid) and hydrogen peroxide. The U.S. Air Force formulated an aluminum/hydrazine gelled fuel called alumizine for liquid rocket engine systems (ref. 5) and a beryllium/hydrazine gelled fuel called beryllizine for use in advanced propulsion systems from 1959 to 1966 (ref. 6). Similarly, the U.S. Navy conducted safety related gelled propellant programs from 1959 to 1965 with hydrazine type fuels and nitric acid. In the period from 1960 to 1970 , the Navy. successfully formulated NOTSGEL-A (60 wt \% Al in hydrazine) and NOTSGEL-Z ( $80 \mathrm{wt} \% \mathrm{Zr}$ in hydrazine) in their High Energy Bi-Propellant Fuels Program (refs. 7 and 8). More recently the U.S. Army has funded programs to formulate, characterize, and evaluate high-energy liquid propellants, and developed the rheologicaliy matched propeliant combination of MICOM (Missile Command) gel and IRFNA gel (ref. 9).

In the early 1970's interest was revived in metallized liquid hydrocarbon fuels due to the advantage of higher volumetric heat of combustion with respect to the neat liquid hydrocarbon fuels that were used for alrbreathing systems. From 1969 to 1973, the U.S. Navy developed hydrocarbon-gel fuels with 60 wt $\%$ carbon black, 75 wt \% aluminum, and 65 wt \% boron carbide during a High Energy Ramjet Fuels program (refs, 7 and 10). Carbon slurry fuel formulation work was also funded by the U.S. Alr Force, NASA Lewis Research Center and the Department of Energy (DOE) in the late 1970s and early 1980s. The patented SF2 carbon slurry fuel (carbon in JP-10) was formulated and its properties were characterlzed as a part of this work. The energy crisis also supported the need for fuel alternatives for highway transportation, and other carbon slurry 
fuels were developed for this application (refs. 11 and 12). Investigations of metallized hydrocarbon propellants continue today, but much of the work is sensitive in nature due to its military application and is not reported here.

The NASA Lewis Research Center is presently investigating the aluminum/ RP-1/oxygen (AI/RP-1/ 2 ) propellant combination for rocket engine applications. Previous propellant development work in the area of aluminized fuels has focused on airbreathing engine combustion where only limited success has been achieved. The additional study of aluminum-hydrocarbon propellant is required for the development of a rocket fuel, not an airbreathing fuel, and the successful demonstration of injection, ignition, and combustion within a high temperature-pressure rocket engine. The objective of the research investigations is to formulate and characterize the properties of stable Al/RP-1 gels with acceptable rheological properties. The Al/RP-l fuel is of specific interest to NASA for several reasons. Aluminum addition can potentially improve rocket performance because of its density and high combustion energy with oxygen (ref. 13). Aluminum is also nontoxic and safer to handle than other promising metal fuels such as beryllium and lithium. RP-l (Kerosine, MIL-P-25576C) is a high density storable liquid hydrocarbon that has been previously used as a rocket propellant and is currently being evaluated for advanced space transportation booster engines. This report summarizes recent efforts by NASA Lewis to formulate, stabilize, and characterize the properties of $A$ I/RP-1 fuels.

\section{DISCUSSION}

The suspension of a solid material in a neat liquid involves numerous considerations and trade-offs in order to maximize the potential benefits of the fuel. Table I summarizes fuel properties which should be considered in formulating a metallized propellant. The formulation, stability, and rheological properties are dependent upon the physical and chemical properties of the metallic phase, liquid hydrocarbon, and the stabilizing additives and their interactions in solution. Two important properties in formulating metallized propellants for rocket propulsion applications are the bulk density and specific impulse of the propellants. The combination of these two parameters must be optimized to maximize delivered payload. Bulk density increases with the addition of the dense solid metallic phase and specific impulse may improve upon metal addition. It is desirable to minimize solid particle size ( $\leq l \mu m$ mean particle size) for efficient combustion; however, the smaller the particle size, the more particulates that are required for a given heat of combustion. In general, less gellant is required with the smaller particle size and viscosity increases with increasing number of particulates. The other formulation properties are characteristics primarily derived from the liquid carrier.

The physical, chemical, and thermal stability of a metallized propellant must also be maximized. Physical stability refers to the disabling interactions (agglomeration, flocculation, or aggregation) of the solid phase while in suspension. Definitions of terms are located in the appendix. While these processes weaken the physical stability of the Al/RP-I fuels, the gelation of liquid hydrogen depends upon the surface interactions of a large number of finely divided particles (ref. 14). As the small particulates grow in size due to these particle-particle interactions (which are dependent upon particle morphology), they will settle under normal gravimetric conditions. Hence, stabilizing agents (surfactants and gellants) and/or bimodal (two size) particle 
distributions are often required to account for these forces (see appendix). Surfactants can prevent flocculation via stearic hinderance with the adsorption of a monolayer onto the particle. The adsorbed monolayer overcomes the van der Waals forces that create the attractive migration force among particles by assuming an induced charge which repels particles similarly coated by the surfactant. Gellants and bimodal particle distributions can prevent agglomeration and aggregation by forming a matrix or network about deflocculated particles. Gellants construct the three-dimensional matrix by the intermixing of their long polymeric chains. Bimodal particle distribution develops the network by the flocculating forces of smaller particulates around larger particles. However, the addition of stabilizing components to the metallized fluid must be minimized because their introduction complicates the preparation procedure and tends to increase viscosity and chemical instability. In general, stabilizing components also represent the lowest energy portion of the propellant combination.

Chemical instability results from chemical reactions between the (sometimes numerous) formulation components, impurities (sulfur, water, etc.), and additives (drying agents, vapor pressure reducers, etc.) in the metallized propellant. Additives and impurities in metallized propellants should be minimized as they add to the potential chemical imbalance of the system. Temperature variations may promote chemical reaction rates and vaporization losses which in turn, could increase syneresis, pressure development, bulk growth rate, and physical and chemical instability. Thermally stable metallized fuels are generally produced by trial and error formulation where the concentrations of the stabilizing agents and additives are varied parametrically.

The viscosity of metallized propellants is the most difficult property to control in formulation but is critical since it determines the final propellant's flow characteristics. The addition of stabilizing agents to the solidliquid mixture typically creates an internal structure that requires a finite yield stress to initiate flow and a nonlinear shear stress-shear rate relationship that is often time-dependent. Figure 1 shows shear stress-shear rate relationships for various types of these time-independent non-Newtonian fluids. $V$ iscosity is the ratio of shear stress to shear rate. Figure 2 illustrates time-dependent non-Newtonian viscoelastic fluid behavior. Time-dependent behavior is illustrated by uniformly increasing shear rate to a maximum limit and then uniformly decreasing shear rate to a minimum limit. Thixotropic fluids demonstrate a decrease in shear stress with time at a constant shear rate. Rheopectic fluids demonstrate an increase in shear stress with time at a constant shear rate. A detailed review of non-Newtonian flow and heat transfer is contained in references 15 and 16 . The ideal metallized propellant from a rheological standpoint is a reproducible yield pseudoplastic thixotrope (shear thinning) that approaches Newtonian behavior at high shear rates. The yield point, finite stress required to initiate flow, provides a measure of spill and tank rupture safety since a minimum shear force is required for flow. Shear thinning behavior is desired so that the energy required to transport the material diminishes with shear rate and time. Newtonian behavior is desired at high shear rates (i.e. propulsion system operational shear rates) so the rheological characteristics of the fuel and oxidizer match as closely as possible and to assist in maintaining a constant mass flow rate. The yield point and viscosity, especially at low temperatures, should be minimized by minimizing the concentration of the stabilizing agents, minimizing the distortion of particle shape during formulation, and minimizing the solids concentration and particle surface area per unit volume. 
To achieve successful fuel formulations with uniform particle dispersion, the aggregates, flocculates, and agglomerates of the metallic powder must be broken down to the elemental particle size. The milling process used to accomplish this must be conducted with minimal flattening of the particulates since longer and flatter platelets will produce a more viscous product. Figure 3 shows some types of laboratory equipment typically used during the formulation of metallized propellants. The high shear mixer is used to uniformly disperse the solids and additives into the liquid propellant. The rolling ball mill is charged with cylindrical grinding media to slowly break up the flocculated particulates. Finally, the centrifuge is used for fuel stability testing.

Physical, chemical, and thermal stability are requirements of an acceptable metallized propellant. The propellant must be stable during all phases of the fuel formulation process and for storage of the propellant. Static shelf life tests and accelerated storage stability tests can be used to evaluate the stability of a propellant formulation. Static shelf life tests can be used to evaluate the long term physical, chemical, and thermal storage stability of a propellant formulation under actual storage conditions. In a static shelf life test the metallized propellant is sealed into a storage vessel which is exposed to a thermally varying environment. The vessel should not contain any ullage for the liquid carrier to evaporate and condense and, hence, yield false stability information. Instability of the suspension with time is witnessed by supernatant fluid at the top of the container and solid density gradients along the container height. Although these static shelf life tests are easy to conduct, useful results may take 1 to 5 years to attain.

Accelerated storage stability tests can be used to rapidiy evaluate the physical stability of the propellant. Physical stability is achieved by limiting the amount of aggregation, flocculation, and agglomeration that creates larger particles which settle with gravity. Solid particulates tend to settle under their own mass because they are typically more dense than the liquid carrier. Accelerated storage stability tests are based on Stokes Law. Stokes law, which governs the rate of settling of a single particle in a gravitational field, states that the rate of fall is proportional to the gravitational field strength (ref. 17). Modified Stokes law extends this proportionality to concentrated suspensions undergoing hindered settling. A centrifuge, such as the one shown in figure 3 , can be used to produce an artificial gravitational field whose centrifugal field strength may be derived from:

$$
G=1.118 \times 10^{-5}(\mathrm{rpm})^{2}(r)
$$

where rpm is the operating revolutions per minute of the centrifuge and $r$ is the radius (in centimeters) of the centrifuge as measured from the center of the centrifuge to the tip of the test tube. $G$ is expressed as multiples of the gravitational constant, $g\left(9.8 \mathrm{~m} / \mathrm{s}^{2}\right)$. Stability values are reported in terms of a dimensionless ratio of concentrations, $\mathrm{C} / \mathrm{C}^{\circ}$, where $\mathrm{C}^{\circ}$ is the original solids concentration and $C$ is the solids concentration of the top $1 \mathrm{ml}$ after centrifuging. $C / C^{O}$ values determined at a particular centrifugal field strength and centrifuge time duration can be related to a long term storage stability period.

Chemical instabilities are witnessed during fuel processing by gas formation from chemical reactions promoted by the incompatibility of the propellant components. A short term test for chemical stability is to contain the 
propellant sample in a sealed container and measure the pressure increase during short term storage. An adverse environment may be imposed on the fuel sample by ovens or refrigeration units to test for thermal instabilities.

The flow curves for the metallized propellants were acquired with rotational viscometers. A Brookfield viscometer was used for quick evaluation or screening of gellants and surfactants to verify an adequate yield point for the suspension of solids and acceptable viscosity for flow. The Brookfield viscometer measures the torque (proportional to shear stress) of a rotating spindle (rpm proportional to shear rate) in a large volume to determine viscosity values. Higher shear rate viscosity measurements were determined with a Haake rotational viscometer. The Haake is less sensitive to low shear rates in comparison to the Brookfield, however it can be much more accurate and precise. The Haake viscometer which was used measures the torque (proportional to shear stress) of a rotating bob (rpm proportional to shear rate) in a concentric cylindrical arrangement. Different ranges of viscosity can be measured by utilizing the different available geometries.

\section{RESULTS}

\section{Fuel Formulation}

Propellant formulation efforts were conducted to prepare Al/RP-l fuels with the aforementioned properties desired for metallized propellants. Twelve different compositions of AI/RP-1 fuel were formulated with 5 and $16 \mu \mathrm{m}$, atomized aluminum powder in RP-1 for a total of 24 fuel samples. All formulations were produced by the same preparation technique with the same proportion of additives. The total solids concentration varied from 5 to $60 \mathrm{wt} \%$ at $5 \mathrm{wt} \%$ increments. The metallized propellant composition and component concentrations in weight percent for both the 5 and $16 \mu \mathrm{m} \mathrm{Al/RP}-1$ gels are given in table II. Density values for the 5 and $16 \mu \mathrm{m} \mathrm{Al/RP-1}$ gels are tabulated with the stability and rheological information in tables III and IV, respectively. Manufacturer specifications suggest that the 400 and 200 series aluminum powders should have average particle sizes of 5 and $16 \mu \mathrm{m}$, respectively. However, the results reported in table $V$ of a particle size image analysis, a standard optical sizing technique, suggest that the mean particle size is smaller than the manufacturer specifications. The 200 series aluminum powder contains a large number of very fine particles, lowering the mean particle size. This can be seen from a scanning electron micrograph of the 200 series aluminum powder as shown in figure 4. The irregular, nonspherical shape of the aluminum powder particles is also evident.

Fuel formulation efforts were also conducted to prepare an RP-1 gel (unmetallized) using a water soluble resin described in reference 18 . The composition of the RP-1 gel is listed in table VI. The resin is an acrylic acid polymer that is insoluble in kerosene, but when added together with the laurylamine, the resin becomes hydrophobic and mildly soluble in kerosene. The methyl alcohol is added to adjust the solubility of the kerosene so that the gellant/amine combination can go into solution. The RP-l gel was prepared by first adding the laurylamine to the RP-1. The resin was then carefully dispersed into this mixture, and the mixture was agitated to a thin homogeneous solution. Finally, the methyl alcohol was added with vigorous agitation using 
a high shear mixer to blend the mixture to uniformity. The resulting RP-1 gel was highly viscoelastic. Further work focused on decreasing the RP-i gel viscosity by adjusting the concentrations of the resin, laurylamine, and methyl alcohol.

\section{Stability Tests}

The accelerated storage stability tests on the Al/RP-1 metali ized fuels were conducted at a centrifugal field strength of $96 \mathrm{~g}$ for $6 \mathrm{hr}$. Solids concentration of a sample was determined by a mass analysis before and after the evaporation of the liquid phase by an oven. Gelled physical states were achieved in fuels with solids loadings greater than $50 \mathrm{wt} \%$, based on overnight visual observations of density gradients, for both the 5 and $16 \mu \mathrm{m}$ aluminum powder. However, $\mathrm{C} / \mathrm{CO}^{\circ}$ stability values were well below the maximum value of one after centrifuging. Stability values for the Al/RP-I metallized propellant formulations are listed in tables III and IV. Physical separation occurred for all fuels below 50 wt \% based on overnight visual observations of density gradients. Better stability was achieved with the 16- 4 m grade aluminum samples because the surfactant additives are working more efficiently on the smaller surface area per unit volume particles. This finding does not necessarily imply larger particles are required for stability because the physical instabilities of the formulations originated from a misproportioning of stabilizing agents. Chemical instabilities during fuel formulation, although not fully conclusive evidence of chemical stability, were not detected with the Al/RP-l gels. Thermal stability tests were not conducted.

\section{Rheology Tests}

Brookfield apparent viscosity values for the twenty-four samples are reported in tables III and IV. The $0.3 \mathrm{rpm}$ reading corresponds to a yield point value, and the $60 \mathrm{rpm}$ (less than $16 \mathrm{~s}-1$ ) reading corresponds to the highest shear rate of the instrument. The viscosity values were measured after agitation at $60 \mathrm{rpm}$ until a steady reading was obtained and then decreased to $0.3 \mathrm{rpm}$ for the yield point reading. The viscosities decreased with solids loading for the gelled samples and had erratic behavior for the unstable separated samples of both test series. Experimental viscosity results for propellants with 45 wt \% and below solids concentration are questionable because of the instability of the samples. The fuels with 16- 4 m aluminum powder had higher viscosities than those with 5-um aluminum powder at the same solids loading. The stabilizing agents worked better with the lower surface area per unit volume particles $(16-\mu \mathrm{m})$ because less of the liquid carrier was immobilized by the particulates.

The Haake yield point and viscosity values for the Al/RP-1 fuel formulations are listed in tables III and IV. The yield point values are peak shear stress values (gelled samples only with overnight standing) achieved upon a ramping increase of shear rate to $117 \mathrm{~s}-1$ (10 percent max shear rate). Shear stress peaks for Al/RP-l fuels with $60 \mathrm{wt} \%$ solids concentration of 5 and $16 \mu \mathrm{m}$ powder are shown in figures $5(2)$ and $6(a)$, respectively. The tabulated viscosity values are reported with a corresponding shear rate from the down ramping line (where possible) because the viscosity is not constant with shear (non-Newtonian). Haake flow curves to the maximum shear rate $(1170 \mathrm{~s}-1$ ) for the Al/RP-1 fuels with 60 wt \% solids concentration of 5 and $16 \mu \mathrm{m}$ powder are 
shown in figures $5(b)$ and $6(b)$. Figures $5(a)$ and $6(a)$ correspond to the 0 to $117 \mathrm{~s}-1$ shear rate range of figures $5(b)$ and $6(b)$ since these flow curves were taken at the same time shortly after formulation of the fuels. A second set of measurements was made approximately 5 months after the original measurements with a similar Haake viscometer, but different sensing heads, to investigate changes in the rheological behavior of the fuels with time. This second set of Haake flow curves for fuel samples with $60 \mathrm{wt} \%$ solids loading of 5 and $16 \mu \mathrm{m}$ aluminum powder is provided in figures $5(c)$ and $6(c)$, respectively. A comparison of viscosity values with time for 45 wt \% solids concentration and above is tabulated in tables VII and VIII.

The results of the rheological investigations of the Al/RP-1 fuels are qualitative because of the observed instabilities, the use of different measurement procedures and the apparent evaporation loss of the liquid phase during storage of the fuels. Stable gelled Al/RP-l fuels may behave differently depending upon the method of stabilization and additive concentrations. However, several general conclusions were drawn from these investigations. The yield points of the Al/RP-1 fuels increase with solids loading due to the increased immobilization of the liquid carrier by the additional solids. The yield points also increase with particle size at equal solids concentrations because the stabilizing agents become more effective as the surface area per unit volume of the particle decreases and, hence, less liquid phase is immobilized. The yield points diminish with time due to the predicted physical instabilities and potentially from the long term chemical and thermal instabilities. In general viscosity increased with time at equal shear rates and solids loading due to the apparent evaporation of the liquid phase. Viscosity decreased with increasing shear rate (the fuels were shear thinning) due to the breakdown of the gel structure, and thixotropic and rheopectic behavior of the fuel was observed. Finally, at equal shear rates, viscosity decreased with decreasing solids loading because the liquid carrier is less confined by the particulates.

\section{CONCLUDING REMARKS}

Research efforts were conducted at the NASA Lewis Research Center to formulate and characterize the properties of Al/RP-1 and RP-1 gels for rocket propulsion applications. The AI/RP-I fuel has been previously identified as potentially improving propulsion system and vehicle performance because of the increased energy and density of aluminum relative to the neat liquid fuel. Safety advantages are also possible with these propellants in certain applications because of the gelled physical state of the propellant. While a final Al/RP-1 fuel formulation has not been produced to date, research efforts continue to formulate gelled and metallized fuels and characterize their stability and rheological properties.

Numerous considerations with respect to rocket propulsion applications were presented that influence the final metallized propellant formulation properties. The fuels must be physically, thermally, and chemically stable during all phases of the fuel formulation process and for storage of the propellant. Propellant formulation efforts were conducted to prepare Al/RP-1 and RP-1 gelled fuels. Twenty-four different compositions of Al/RP-1 fuels were formulated with 5 and $16 \mu \mathrm{m}$ aluminum powder in RP-1. All Al/RP-1 formulations were produced by the same preparation technique with the same proportion of additives. Accelerated storage stability tests were conducted to evaluate the 
stability of the propellant. Physical instability of the Al/RP-l samples was predicted from $96 \mathrm{~g}$ accelerated storage stability tests. Physical separation of the solids occurred in fuels with less than 50 wt $\%$ solids concentration because of a misproportioning of additives at the lower solids concentrations. The unmetallized RP-1 gels, which were formulated by a different technique than the Al/RP-1 gels, were stable.

Different non-Newtonian rheological behaviors were identified and viscosity measurement techniques and instruments were discussed. Due to the observed physical instabilities of the Al/RP-I gels, the rheological results were qualitative and different behavior may be expected from stabilized fuels. The yield points were observed to increase with solids loading and particle size and decrease with time. The rheological characteristics of the fuels varied with solids concentration, with the fuels displaying both thixotropic and rheopectic gel behavior. The unmetallized RP-l gels demonstrated highly viscoelastic rheological behavior. The research efforts required to characterize the stability and rheological properties of metallized propellants for. rocket propulsion applications are described in this report. 
Absolute Viscosity - ratio of shear stress to shear rate that assumes an absolute value for all shear rates, i.e. Newtonian fluids.

Adsorption - adhesion of an extremely thin layer of molecules to the surfaces of solid bodies with which they are in contact.

Agglomeration - process of solid particles reaching a lower free energy (entropy) state by joining at their crystal edges.

Aggregation - process of solid particles reaching a lower free energy (entropy) state by joining at their crystal faces.

Apparent Viscosity - ratio of shear stress to shear rate that assumes a discrete value at each shear rate, i.e. Non-Newtonian fluids.

Bimodal Particle Distribution - two particle size system that uses the smaller solid phase to stabilize the larger solid phase.

Bulk Growth - increase in propellant volume due to gas evolution from the chemical incompatibility of propellant components.

Dispersion - uniform scattering of material in a fluidic media.

Emulsion - dispersion of fine particles or globules of a liquid in a liquid.

Flocculation - process of solid particles reaching a lower free energy (entropy) state by joining in loosely bound structures by van der Waals forces.

Gel - pure liquid semisolidified by the addition of a polymeric gellant additive.

Hydrophobic - lacking affinity for water.

Morphology - the study of external structural shape and size of a solid particle.

Newtonian - fluids which exhibit a linear shear stress-shear rate relationship, i.e. constant viscosity.

Non-Newtonian - fluids which exhibit a nonlinear shear stress-shear rate relationship, i.e. variable viscosity.

Pseudoplastic - fluids whose apparent viscosity decreases with increasing shear under isothermal conditions, i.e. shear thinning.

Rheology - science of deformation and flow.

Rheopectic - fluids that exhibit a reversible increase in shear stress with time at a constant rate of shear under isothermal conditions.

Slurry - fluidic solid-liquid system. 
Stearic Hinderance - separation by virtue of induced charge and consequent particle repulsion.

Supernatant - neat fuel overlying metallized propellant deposited by settling or centrifugation.

Surfactant - dispersing medium that is adsorbed onto the surface of a particle to prevent flocculation.

Suspension - system consisting of a solid dispersed in a liquid.

Syneresis - separation of liquid from a gel caused by contraction.

Thixotropic - fluids that exhibit a reversible decrease in shear stress with time at a constant rate of shear under isothermal conditions.

Ullage - the amount that a container lacks of being full.

Viscoelastic - fluids that show a partial elastic recovery upon the removal of a deforming shear stress.

Yield Point - finite stress that is required to initiate flow. 


\section{REFERENCES}

1. Arbit, H.A., Clapp, S.D., Dickerson, R.A., and Nagai, C.K., "Lithium-Flourine-Hydrogen Propellant Study," R-7257, Rockwell International Corp., Canoga Park, CA, 1968, NASA CR-72325.

2. Zurawski, R.L., and Green, J.M., "An Evaluation of Metallized Propellants Based on Vehicle Performance," AIAA Paper 87-1773, June 1987. (NASA TM-100104.)

3. Burdette, G.W., and Couch, D.H., "Non-Newtonian Rocket Fuels," U.S. Naval Ordnance Test Station, China Lake, CA. [Declassified by G.W. Burdette June 14, 1977 in accordance with E.0. 11652.]

4. Pinns, M.L., Olson, W.T., Barnett, H.C., and Breitwieser, R., "NACA Research on Slurry Fuels," NACA Report 1388, 1958.

5. Aitken, A.J., "Metallized Thixotropic Propellants," BSD-TDR-63-122, Aerojet-General Corp., Sacramento, CA, June 1963. (Avail. NTIS, $A D-338493$ ).

6. Aitken, A.J., Fish, W.R., and Suder, J.K., "Development of High-Energy Metallized Propellants," AFRPL-TR-66-230, Sept. 1966. (Avail NTIS, AD-377684.)

7. Burdette, W., "A. Review of Navy Gelled Fuel Programs," 17th JANNAF Combustion Meeting, Workshop on the Combustion of Slurry Fuels in Airbreathing Systems, Hampton, Virginia, Sept. 1980.

8. Burdette, G.W., Hoffman, H.J., and Nyberg, D.G., "Gelled Liquid Propellants With Improved Performance," U.S. Naval Ordnance Test Station, China Lake, CA. [Declassified by G.W. Burdette June 14, 1977 in accordance with E.O. 11652.]

9. Allan, B.D., "A Gelled Oxidizer for Tactical Missiles," U.S. Army Missile Command, Redstone Arsenal, Huntsville, AL, 1982. (Avail. NTIS, AD-C028699L.)

10. Bryant, J.T., and Burdette, G.W., "Ramjet Fuel Studies, Part 1 - Carbon," NWC-TP-4810, Parts 1-3, U.S. Naval Weapons Center, China Lake, CA, July

1971. (Avai1. NTIS, AD-886596L, AD-913289L, AD-B016607L.)

11. Ryan, T.W., III, and Dodge, L.G., "Development of Carbon Slurry Fue is for Transportation (Hybrid Fuels - Phase 2), "SWRI-6948, Southwest Research Institute, San Antonio, TX, May 1984, DOE/NASA/0263-1, NASA CR-174659.

12. Ryan, T.W., III, Callahan, T.J., Likos, W.E., Moses, C.A., and Dodge, L.G., "Alternative (Hybrid) Fuels for Highway Transportation, Vol. 1," Southwest Research Institute, San Antonio, TX, 1980.

13. Zurawski, R.L., "Current Evaluation of the Tripropellant Concept," NASA TP-2602, 1986. 
14. Sindt, D.F., Ludtke, P.R., and Daney, D.E., "Slush Hydrogen Fluid Characterization and Instrumentation," NBS-TN-377, National Bureau of Standards, Boulder, CO, Feb. 1969.

15. Skelland, A.H.P., Non-Newtonian Flow and Heat Transfer, John Wiley \& Sons Inc., New York, 1967, pp. 1-238.

16. Bird, R.B., Stewart, W.E., and Lightfoot, E.N., Transport Phenomena, John Wiley \& Sons, New York, 1960, pp. 3-29.

17. Adamson, A.W., A Textbook of Physical Chemistry, 2nd ed., Academic Press, New York, 1979.

18. The B.F. Goodrich Company, "Carbopol Water Soluble Resins," Technical Paper GC-67, B.F. Goodrich Company, Specialty Polymers \& Chemicals Division, 1987.

TABLE I. - SUMMARY OF METALLIZED PROPELLANT PROPERTY CONSIDERATIONS

\begin{tabular}{|c|}
\hline Formulation properties \\
\hline $\begin{array}{l}\text { Optimize propellant bulk density and specific impulse } \\
\text { to maximize delivered payload } \\
\text { Maximize reproducibility of composition } \\
\text { Maximize formulation component availability }\end{array}$ \\
\hline $\begin{array}{l}\text { Minimize particle size } \\
\text { Minimize volatility (i.e. high boiling point) } \\
\text { Minimum flash point requirement of } 60^{\circ} \mathrm{C} \\
\text { (140 of, i.e. combustible } 1 \text { iquid) } \\
\text { Minimize toxicity } \\
\text { Minimize cost }\end{array}$ \\
\hline Stability properties \\
\hline $\begin{array}{l}\text { Maximize physical, chemical and thermal stability } \\
\text { Maximize thermal stability temperature range } \\
\text { Maximize combustion energy of stabilizing agents }\end{array}$ \\
\hline $\begin{array}{l}\text { Minimize agglomeration, flocculation, and aggregation } \\
\text { Minimize reactive impurities and additives }\end{array}$ \\
\hline Rheological properties \\
\hline Maximize reproducibility of rheological characteristics \\
\hline $\begin{array}{l}\text { Minimize non-Newtonian rheological behavior } \\
\text { Minimize viscosity, especially at low temperatures } \\
\text { Minimize yield stress } \\
\text { Minimize solids loading } \\
\text { Minimize stabilizing agents concentration } \\
\text { Minimize distortion of particle shape } \\
\text { Minimize particle surface area per unit volume }\end{array}$ \\
\hline
\end{tabular}


TABLE II. - ALUMINUM/RP-1 GEL PROPELLANT COMPOSITIONS

[Values in weight percent.]

\begin{tabular}{|c|c|c|c|c|c|}
\hline $\begin{array}{l}\text { Total } \\
\text { solids }\end{array}$ & $A 1^{a}$ & ST401 ${ }^{b}$ & $R P-1$ & ST $156^{b}$ & ST202 ${ }^{b}$ \\
\hline $\begin{array}{l}60 \\
55 \\
50 \\
45 \\
40 \\
35 \\
30 \\
25 \\
20 \\
15 \\
10 \\
5\end{array}$ & $\begin{array}{r}58.4 \\
53.5 \\
48.6 \\
43.8 \\
38.9 \\
34.1 \\
29.2 \\
24.3 \\
19.5 \\
14.6 \\
9.7 \\
4.9\end{array}$ & $\begin{array}{r}1.6 \\
1.5 \\
1.4 \\
1.2 \\
1.1 \\
.9 \\
.8 \\
.7 \\
.5 \\
.4 \\
.3 \\
.1\end{array}$ & $\begin{array}{l}36.6 \\
41.6 \\
46.6 \\
51.6 \\
56.6 \\
61.6 \\
66.6 \\
71.6 \\
76.6 \\
81.6 \\
86.6 \\
91.6\end{array}$ & 2.0 & $i^{1.4}$ \\
\hline
\end{tabular}

a 400 series or 200 series aluminum powder.

benerically coded additives.

TABLE III. - 5 um (400 SERIES) ALUMINUM/RP-1 GEL PROPELLANT PROPERTIES

\begin{tabular}{|c|c|c|c|c|c|c|c|c|c|}
\hline \multirow[t]{2}{*}{$\begin{array}{l}\text { Formulation } \\
\text { number }\end{array}$} & \multirow[t]{2}{*}{ State $\mathrm{a}^{\mathrm{a}}$} & \multirow[t]{2}{*}{$\begin{array}{l}\text { Percent } \\
\text { solid }\end{array}$} & \multirow[t]{2}{*}{$\begin{array}{c}\text { Stability } \\
C / C^{0}\end{array}$} & \multicolumn{2}{|c|}{$\begin{array}{l}\text { Brookfieldc } \\
\text { viscosity }\end{array}$} & \multirow{2}{*}{$\begin{array}{l}\text { Density }{ }^{d} \\
\text { at } 25^{\circ}{ }^{\circ} \mathrm{C} \text {, } \\
g / c c\end{array}$} & \multirow{2}{*}{$\begin{array}{l}\text { Haake } \\
\text { yield } \\
\text { point, } \\
\text { dynes/cm } 2\end{array}$} & \multirow{2}{*}{$\begin{array}{l}\text { Shear } \\
\text { rate, } \\
\text { sec }^{-1}\end{array}$} & \multirow{2}{*}{$\begin{array}{c}\text { Haake } \\
\text { viscosity, } \\
\text { cp }\end{array}$} \\
\hline & & & & $\begin{array}{l}\eta 60 \\
c p\end{array}$ & $\underset{c p}{\eta 0.3}$ & & & & \\
\hline $\begin{array}{l}942-438 \\
942-450 \\
942-451 \\
942-452 \\
942-453 \\
942-454 \\
942-444 \\
942-445 \\
942-446 \\
942-447 \\
942-448 \\
942-449\end{array}$ & $\begin{array}{c}\mathrm{Gel} \\
\mathrm{Gel} \\
\mathrm{Gel} \\
\text { Separation } \mathrm{f}\end{array}$ & $\begin{array}{l}60 \\
55 \\
50 \\
45 \\
40 \\
35 \\
30 \\
25 \\
20 \\
15 \\
10 \\
5\end{array}$ & $\begin{array}{l}0.40 \\
.17 \\
.15 \\
.16 \\
.11 \\
.15 \\
.07 \\
.21 \\
.25 \\
.20 \\
.33 \\
.28\end{array}$ & $\begin{array}{r}1816 \\
482 \\
179 \\
363 \\
404 \\
103 \\
171 \\
21 \\
21 \\
\text { Rapid s }\end{array}$ & $\begin{array}{rr}10 & 800 \\
2 & 200 \\
300 \\
1800 \\
8200 \\
700 \\
4200 \\
20 \\
60 \\
\text { aration }\end{array}$ & $\begin{array}{l}1.38(1.41) \\
1.31 \\
1.24(1.25) \\
1.17 \\
1.12 \\
1.06 \\
1.01 \\
.974 \\
.935 \\
.898 \\
.865 \\
.833\end{array}$ & $\begin{array}{l}805 \\
138 \\
-- \\
-- \\
-- \\
-- \\
-- \\
-- \\
--\end{array}$ & $\begin{array}{c}1170 \\
819 \\
1170 \\
\square \\
\text { Not mea }\end{array}$ & $\begin{array}{r}257 \\
117 \\
36 \\
122 \\
43 \\
31 \\
23 \\
15 \\
13 \\
\text { surable }\end{array}$ \\
\hline
\end{tabular}

abservation made after standing overnight.

Measurement made, after standing overnight, at $700 \mathrm{rpm}$ for $6 \mathrm{hr}$. $C^{0}$ is original solids concentration and $C$ is centrifuged sample solids concentration.

CMeasured after agitation starting at $60 \mathrm{rpm}$.

doensity values were calculated except values in parenthesis which were measured.

efor gelled samples Haake measurements were made after overnight standing. For the remainder, measurements were made as rapidly as possible.

$f_{A 11}$ results for 45 wt \% and below are questionable due to, physical separation. 
TABLE IV. - $16 \mu \mathrm{m}$ (200 SERIES) ALUMINUM/RP-1 GEL PROPELLANT PROPERTIES

\begin{tabular}{|c|c|c|c|c|c|c|c|c|c|}
\hline \multirow[t]{2}{*}{$\begin{array}{l}\text { Formulation } \\
\text { number }\end{array}$} & \multirow[t]{2}{*}{ State } & \multirow[t]{2}{*}{$\begin{array}{l}\text { Percent } \\
\text { solid }\end{array}$} & \multirow[t]{2}{*}{$\begin{array}{c}\text { Stabilityb } \\
C / C^{0}\end{array}$} & \multicolumn{2}{|c|}{$\begin{array}{c}\text { Brookfieldc } \\
\text { viscosity }\end{array}$} & \multirow{2}{*}{$\begin{array}{l}\text { Densityd } \\
\text { at } 25^{\circ}{ }^{\circ} \mathrm{C} \text {, } \\
\mathrm{g} / \mathrm{cc}\end{array}$} & \multirow{2}{*}{$\begin{array}{l}\text { Haake } \\
\text { yield } \\
\text { point, } \\
\text { dynes } / \mathrm{cm}^{2}\end{array}$} & \multirow{2}{*}{$\begin{array}{l}\text { Shear } \\
\text { rate } \\
\text { sec }^{-1}\end{array}$} & \multirow{2}{*}{$\begin{array}{c}\text { Haake } \\
\text { viscosity, } \\
\text { cp }\end{array}$} \\
\hline & & & & $\begin{array}{l}\eta 60 \\
c p\end{array}$ & $\begin{array}{c}n 0.3 \\
c p\end{array}$ & & & & \\
\hline $\begin{array}{l}942-455 \\
942-456 \\
942-457 \\
942-458 \\
942-459 \\
942-460 \\
942-461 \\
942-462 \\
942-463 \\
942-464 \\
942-465 \\
942-466\end{array}$ & $\begin{array}{c}\mathrm{Gel} \\
\mathrm{Gel} \\
\mathrm{Gel} \\
\text { Separation }\end{array}$ & $\begin{array}{r}60 \\
55 \\
50 \\
45 \\
40 \\
35 \\
30 \\
25 \\
20 \\
15 \\
10 . \\
5\end{array}$ & $\begin{array}{l}0.74 \\
.45 \\
.15 \\
.80 \\
.18 \\
.19 \\
= \\
- \\
- \\
= \\
= \\
-\end{array}$ & $\begin{array}{r}8650 \\
5890 \\
3220 \\
990 \\
251 \\
61 \\
36 \\
16 \\
\text { Rapid }\end{array}$ & $\begin{array}{r}54000 \\
44000 \\
16000 \\
800 \\
400 \\
400 \\
120 \\
- \\
\text { aration }\end{array}$ & $\begin{array}{l}1.38 \\
1.31 \quad(1.33) \\
1.24(1.25) \\
1.17 \\
1.12 \\
1.06 \\
1.01 \\
.974 \\
.935 \\
.898 \\
.865 \\
.833\end{array}$ & 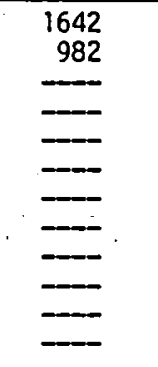 & $\varliminf_{\text {Not im }}$ & $\begin{array}{c}162 \\
104 \\
137 \\
117 \\
28.5 \\
20.9 \\
17.9 \\
9.9 \\
9 \text { surable }\end{array}$ \\
\hline
\end{tabular}

aobservation made after standing overnight.

Measurement made, after standing overnight, at $700 \mathrm{rpm}$ for $6 \mathrm{hr}$. $C^{0}$ is original solids concentration and $C$ is centrifuged sample solids concentration.

CMeasured.after agitation starting at $60 \mathrm{rpm}$.

Density values were calculated except values in parenthesis which were measured.

eFor gelled samples Haake measurements were made after overnight standing. For the remainder, measurements were made as rapidly as possible.

$f_{A 17}$ results for 45 wt \% and below are questionable due to physical separation.

TABLE V. - PARTICLE SIZE IMAGE ANALYSIS RESULTS FOR ATOMIZED ALUMINUM POWDER

\begin{tabular}{|c|c|c|c|}
\hline $\begin{array}{c}\text { Aluminum powder } \\
\text { series number }\end{array}$ & $\begin{array}{c}\text { Average particle size } \\
\text { (manufacturer spec.), } \\
\mu \mathrm{m}\end{array}$ & $\begin{array}{c}\text { Particle } \\
\text { length, } \\
\mu \mathrm{m}\end{array}$ & $\begin{array}{c}\text { Particle } \\
\text { breadth, } \\
\mu \mathrm{m}\end{array}$ \\
\hline 400 & 5 & $3.44 \pm 5.61$ & $2.22 \pm 3.48$ \\
\hline 200 & 16 & $5.95 \pm 4.41$ & $3.75 \pm 2.63$ \\
\hline
\end{tabular}

TABLE VI. - RP-1 GEL COMPOSITION

\begin{tabular}{|l|c|c|}
\hline \multicolumn{1}{|c|}{ Component } & $\begin{array}{c}\text { Chemical } \\
\text { formula }\end{array}$ & $\begin{array}{c}\text { Weight } \\
\text { percent }\end{array}$ \\
\hline Kerosene (RP-1) & $\mathrm{C}_{12} \mathrm{H}_{24}$ & 77.6 \\
Methanol & $\mathrm{CH}_{3} \mathrm{OH}$ & 8.6 \\
Acrylic acid polymer resin & $\left(\mathrm{CH}_{2} \mathrm{CHCOOH}\right)_{n}$ & 3.5 \\
Laurylamine & $\mathrm{C}_{12} \mathrm{H}_{25} \mathrm{NH}_{2}$ & 10.3 \\
\hline
\end{tabular}


TABLE VII. - TIME RHEOLOGICAL PROPERTIES OF 5 um (400 SERIES) ALUMINUM/RP-1 GEL PROPELLANT

\begin{tabular}{|c|c|c|c|c|c|c|}
\hline $\begin{array}{c}\text { Formulation } \\
\text { number }\end{array}$ & $\begin{array}{c}\text { Average Al } \\
\text { particle } \\
\text { size, } \\
\mu \mathrm{m}\end{array}$ & $\begin{array}{c}\text { Solids } \\
\text { loading, } \\
\text { wt \% }\end{array}$ & Test dates & $\begin{array}{c}\text { Haake } \\
\text { yield point, } \\
\text { dynes } / \mathrm{cm}^{2}\end{array}$ & $\begin{array}{c}\text { Shear } \\
\text { rate, } \\
s^{-1}\end{array}$ & $\begin{array}{c}\text { Viscosity, } \\
\eta(c p)\end{array}$ \\
\hline $942-438$ & 5 & 60 & $28 \mathrm{Dec} 87$ & 805 & $\begin{array}{r}585 \\
819 \\
1170\end{array}$ & $\begin{array}{l}341 \\
322 \\
270\end{array}$ \\
\hline $942-439$ & & & 1 Apr 88 & 98 & $\begin{array}{r}585 \\
819 \\
1170\end{array}$ & $\stackrel{400}{-}$ \\
\hline \multirow{2}{*}{$942-450$} & \multirow[t]{2}{*}{5} & \multirow[t]{2}{*}{55} & 17 Nov 87 & 138 & $\begin{array}{r}585 \\
819 \\
1170\end{array}$ & $\begin{array}{l}121 \\
110 \\
\end{array}$ \\
\hline & & & 1 Apr 88 & 37 & $\begin{array}{r}585 \\
819 \\
1170\end{array}$ & $\begin{array}{l}250 \\
238 \\
\end{array}$ \\
\hline \multirow{2}{*}{$942-451$} & \multirow[t]{2}{*}{5.} & \multirow[t]{2}{*}{50} & 1 Dec 87 & - & $\begin{array}{r}585 \\
819 \\
.1170\end{array}$ & $\begin{array}{l}36 \\
36 \\
36\end{array}$ \\
\hline & & & 19 Apr 88 & $-\infty$ & $\begin{array}{r}585 \\
819 \\
1170\end{array}$ & $\begin{array}{l}209 \\
191 \\
175\end{array}$ \\
\hline \multirow{2}{*}{$942-452$} & \multirow[t]{2}{*}{. . 5} & \multirow[t]{2}{*}{45} & 3 Dec 87 & - & $\begin{array}{r}585 \\
819 \\
1170\end{array}$ & $\begin{array}{l}135 \\
132 \\
122\end{array}$ \\
\hline & & & 19 Apr 88 & - & $\begin{array}{r}585 \\
819 \\
1170\end{array}$ & $\begin{array}{r}104 \\
98 \\
92\end{array}$ \\
\hline
\end{tabular}


TABLE VIII. - TIME RHEOLOGICAL PROPERTIES OF $16 \mu \mathrm{m}$ (200 SERIES) ALUMINUM/RP-1 GEL PROPELLANT

\begin{tabular}{|c|c|c|c|c|c|c|}
\hline $\begin{array}{l}\text { Formulation } \\
\text { number }\end{array}$ & $\begin{array}{c}\text { Average A1 } \\
\text { particle } \\
\text { size, } \\
\mu \mathrm{m}\end{array}$ & $\begin{array}{l}\text { Solids } \\
\text { loading, } \\
\text { wt } \%\end{array}$ & Test dates & $\begin{array}{c}\text { Haake } \\
\text { yield point, } \\
\text { dynes } / \mathrm{cm}^{2}\end{array}$ & $\begin{array}{l}\text { Shear } \\
\text { rate, } \\
s^{-1}\end{array}$ & $\begin{array}{l}\text { Viscosity, } \\
\eta(c p)\end{array}$ \\
\hline \multirow{2}{*}{$942-455$} & \multirow[t]{2}{*}{16} & \multirow[t]{2}{*}{60} & 8 Dec 87 & 1642 & $\begin{array}{r}585 \\
819 \\
1170\end{array}$ & $\begin{array}{l}193 \\
177 \\
162\end{array}$ \\
\hline & & & 19 Apr 88 & 293 & $\begin{array}{r}585 \\
819 \\
1170\end{array}$ & $\begin{array}{l}229 \\
206 \\
177\end{array}$ \\
\hline \multirow{2}{*}{$942-456$} & \multirow[t]{2}{*}{16} & \multirow[t]{2}{*}{55} & $15 \mathrm{Dec} 87$ & 982 & $\begin{array}{r}585 \\
819 \\
1170\end{array}$ & $\begin{array}{l}129 \\
117 \\
104\end{array}$ \\
\hline & & & 19 Apr 88 & 268 & $\begin{array}{r}585 \\
819 \\
1170\end{array}$ & $\begin{array}{l}238 \\
217 \\
184\end{array}$ \\
\hline \multirow{2}{*}{$942-457$} & \multirow[t]{2}{*}{16} & \multirow[t]{2}{*}{50} & 14 Dec 87 & - & $\begin{array}{r}585 \\
819 \\
1170\end{array}$ & $\begin{array}{l}168 \\
153 \\
137\end{array}$ \\
\hline & & & $20 \mathrm{Apr} 88$ & - & $\begin{array}{r}585 \\
819 \\
1170\end{array}$ & $\begin{array}{l}275 \\
232 \\
184\end{array}$ \\
\hline \multirow{2}{*}{$942-458$} & \multirow[t]{2}{*}{16} & \multirow[t]{2}{*}{45} & $13 \mathrm{Dec} 87$ & - & $\begin{array}{r}585 \\
819 \\
1170\end{array}$ & $\begin{array}{l}127 \\
123 \\
117\end{array}$ \\
\hline & & & $20 \mathrm{Apr} 88$ & -- & $\begin{array}{r}585 \\
819 \\
1170\end{array}$ & $\begin{array}{l}146 \\
128 \\
136\end{array}$ \\
\hline
\end{tabular}




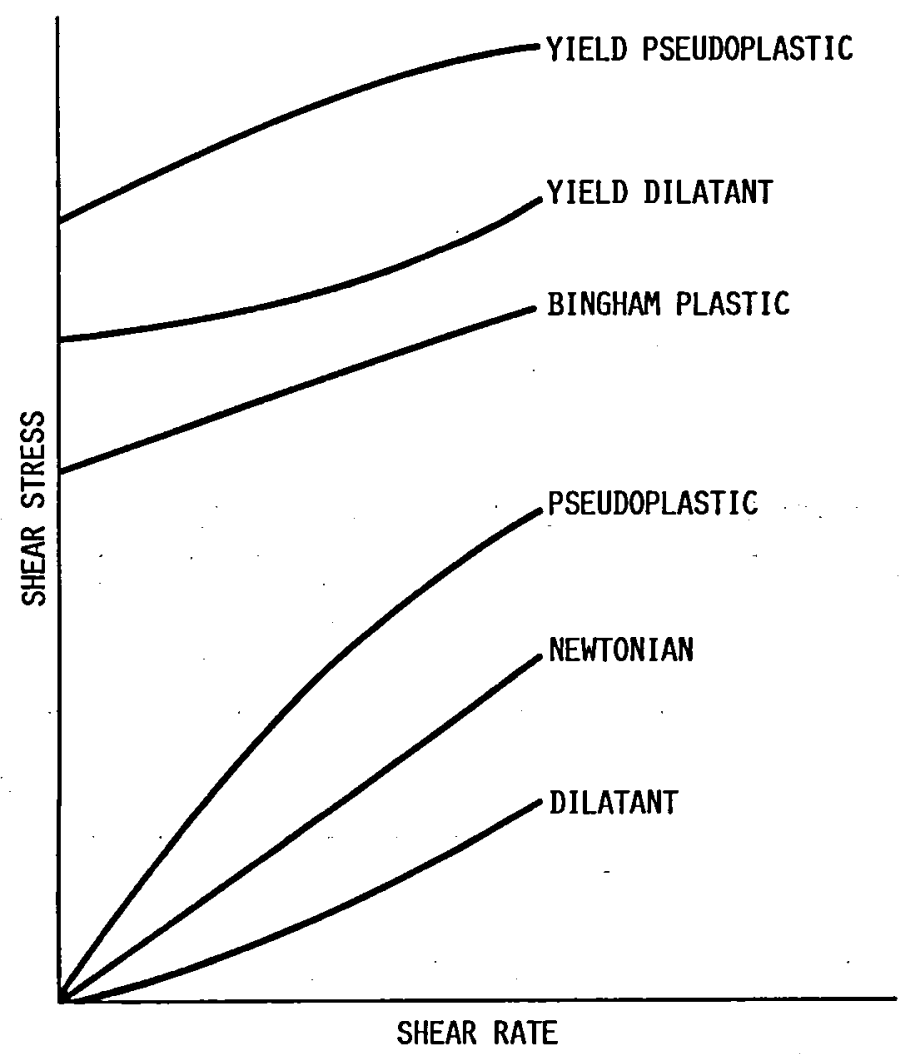

FIGURE 1. - TIME-INDEPENDENT RHEOLOGICAL FLOW CURVES.

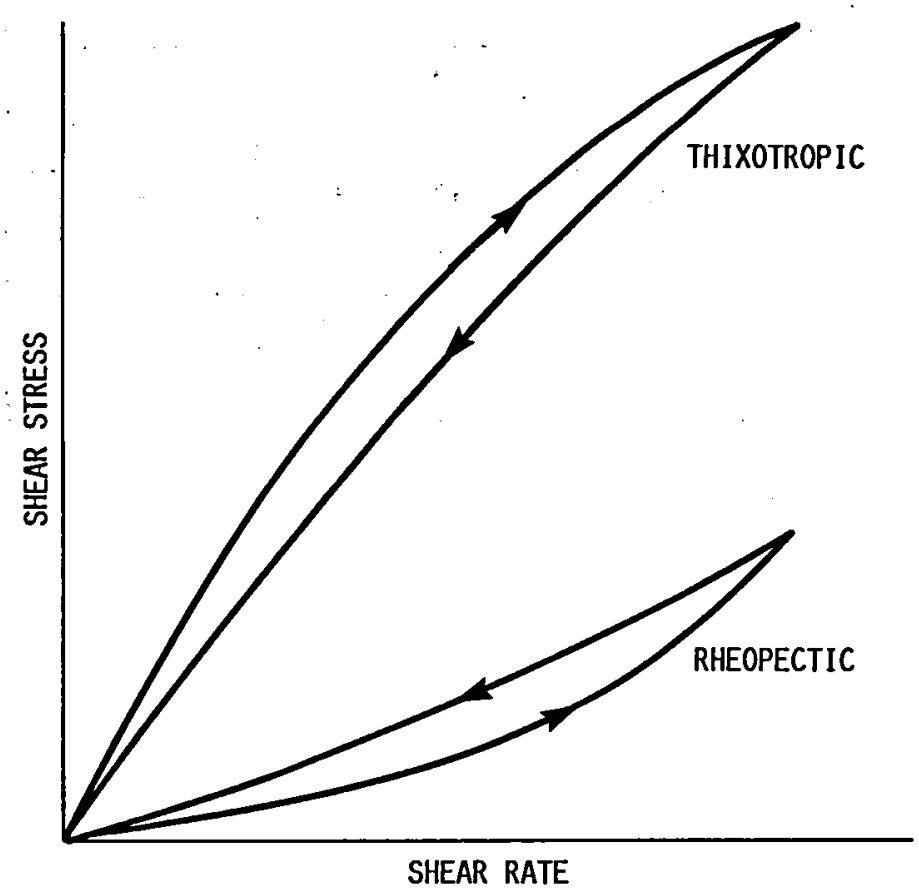

FIGURE 2. - TIME-DEPENDENT RHEOLOGICAL FLOW CURVES. 


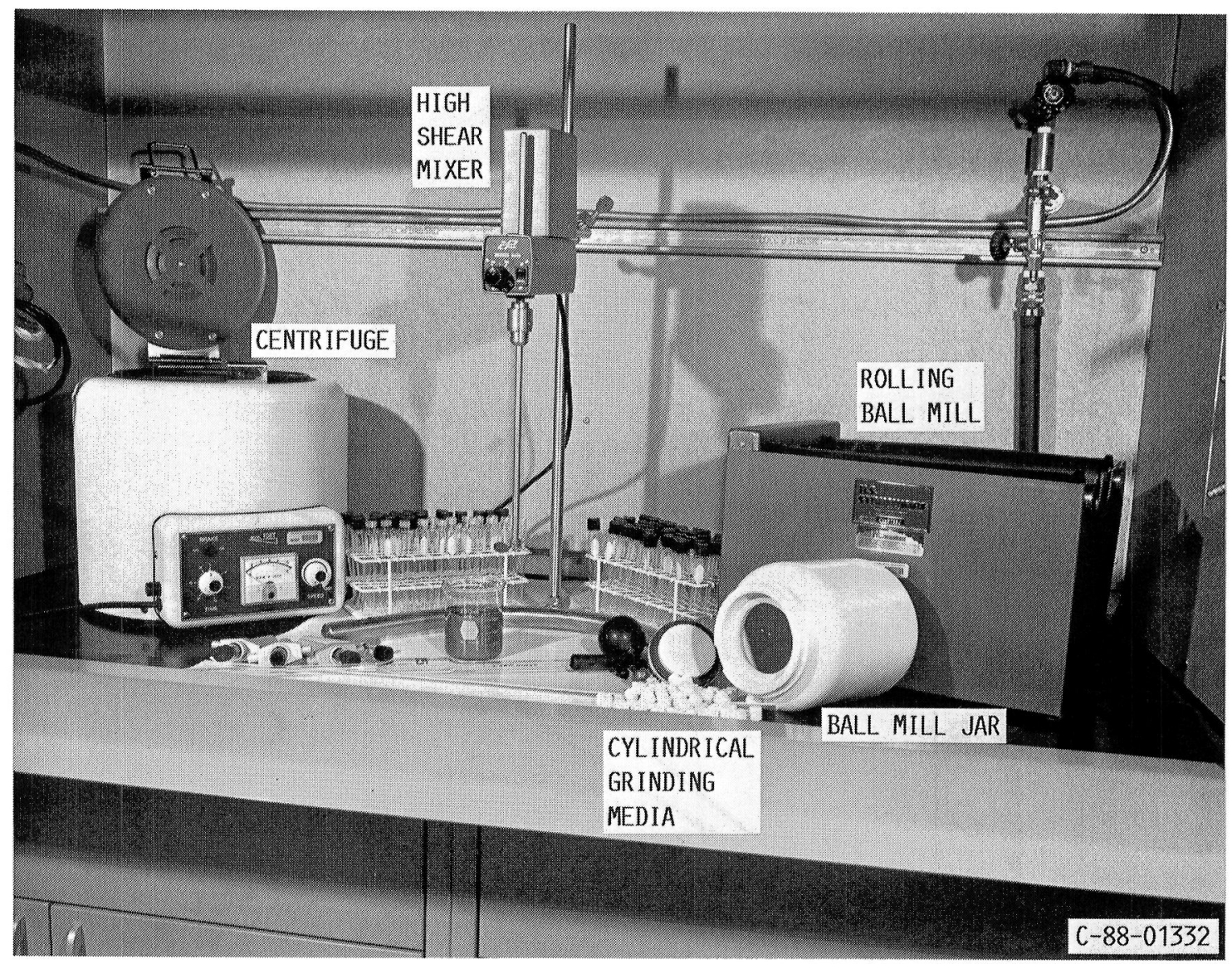

FIGURE 3. - FUEL FORMULATION AND STABILITY TEST LABORATORY EQUIPMENT.

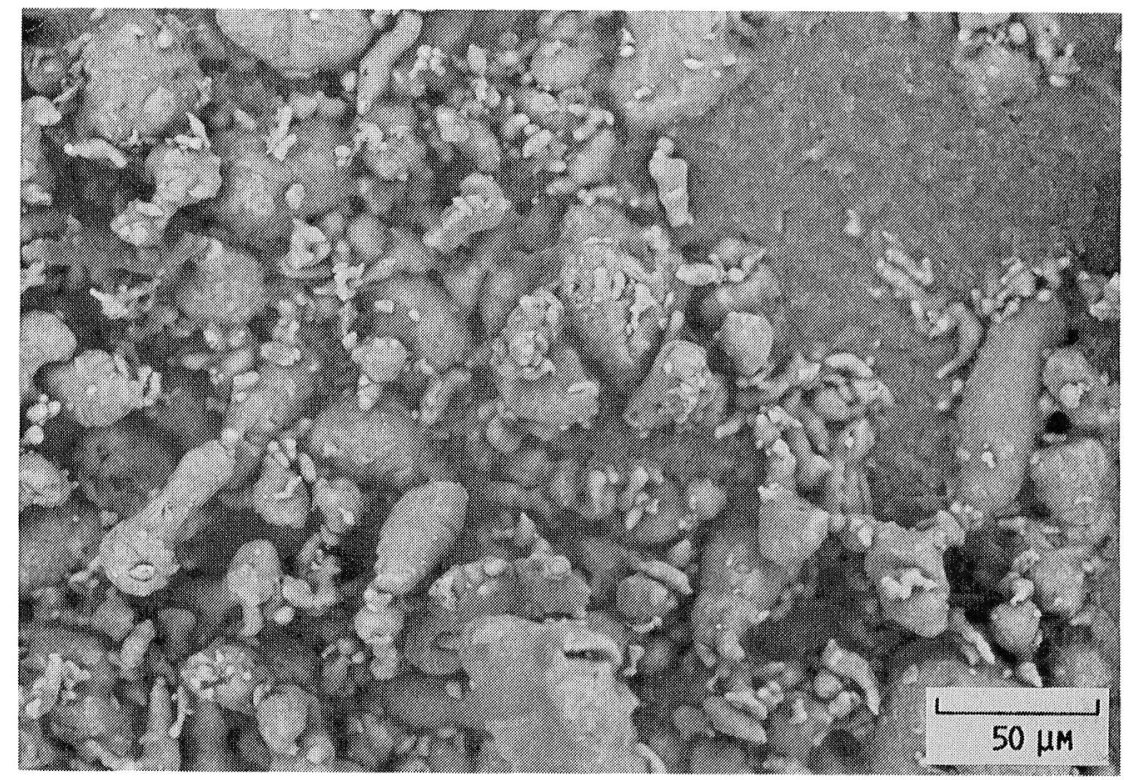

FIGURE 4. - SCANNING ELECTRON MICROGRAPH OF 200 SERIES ALUMINUM POWDER. 


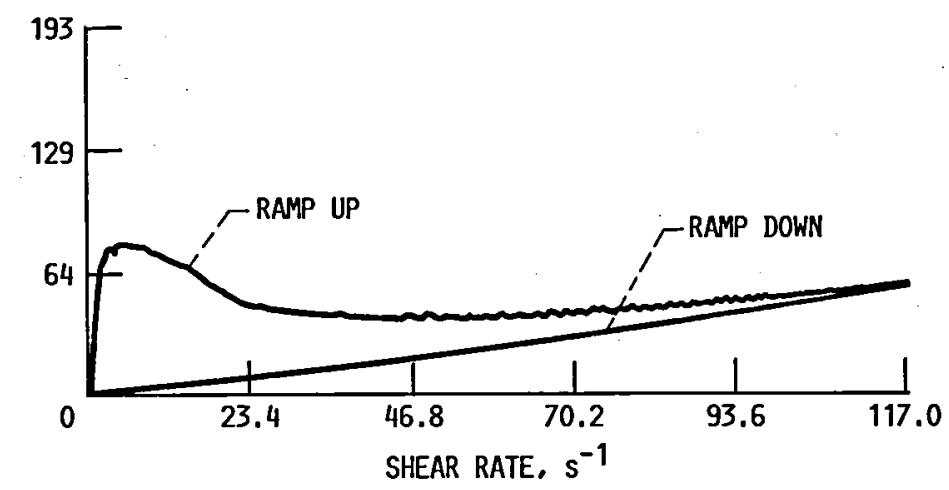

(a) OCTOBER 1987 SHEAR STRESS PEAK, 10\% MAXIMUM SHEAR RATE OF HAAKE MV-1 SENSOR SYSTEM.

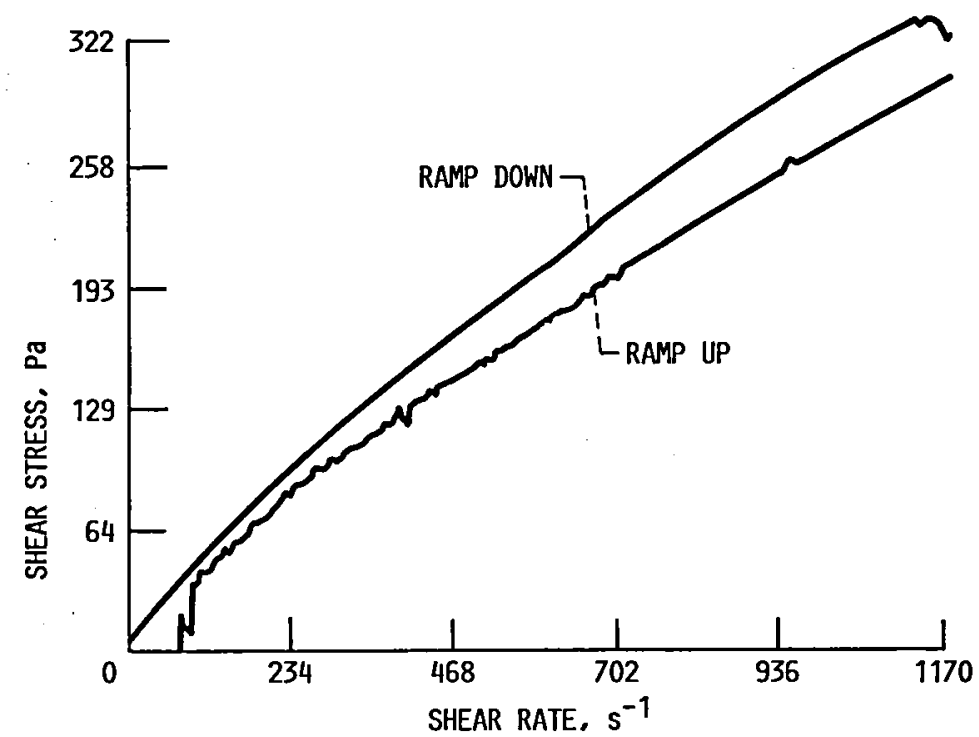

(b) OCTOBER 1987 MAXIMUM SHEAR RATE FLOW CURVE: HAAKE ROTOVISCO RV100, M500 SYSTEM, MV-1 SENSOR SYSTEM.

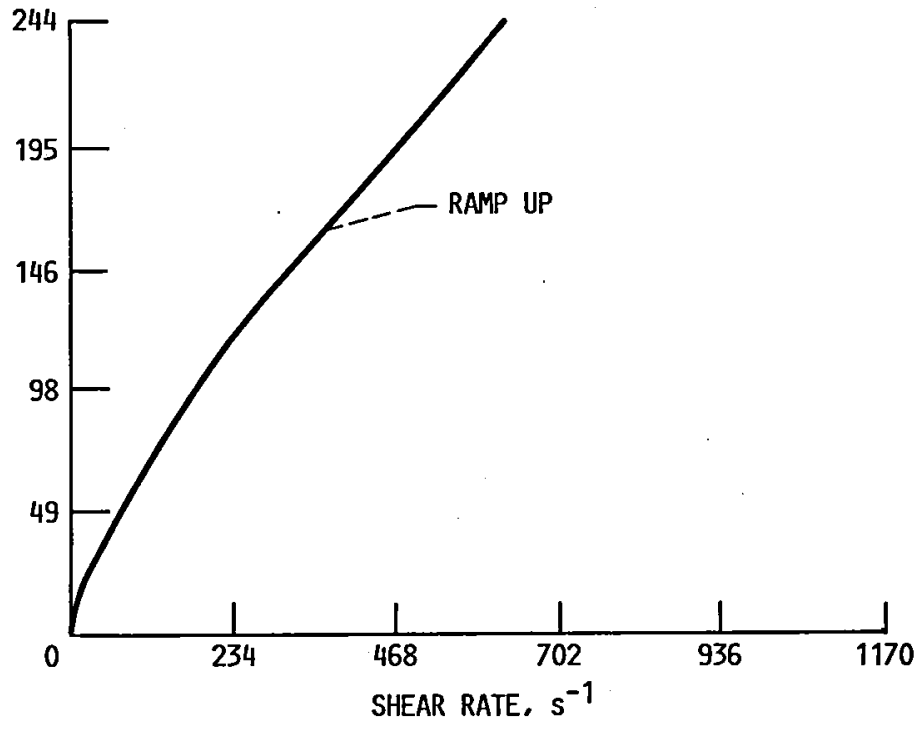

(c) APRIL 1988 MAXIMUM SHEAR RATE FLOW CURVE: HAAKE ROTOVISCO RV100, M500 SYSTEM, MV-HEL SENSOR SYSTEM.

FIGURE 5. - 5 MICRON, 60 wT \%, Al/RP-1 GEL PROPELLANT. 


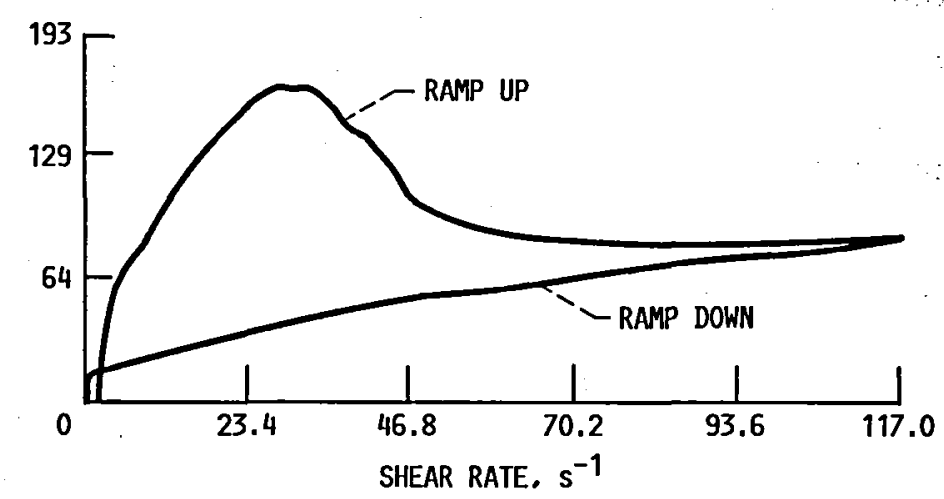

(a) OCTOBER 1987 SHEAR STRESS PEAK, 10\% MAXIMUM SHEAR RATE OF HAAKE MV-1 SENSOR SYSTEM.

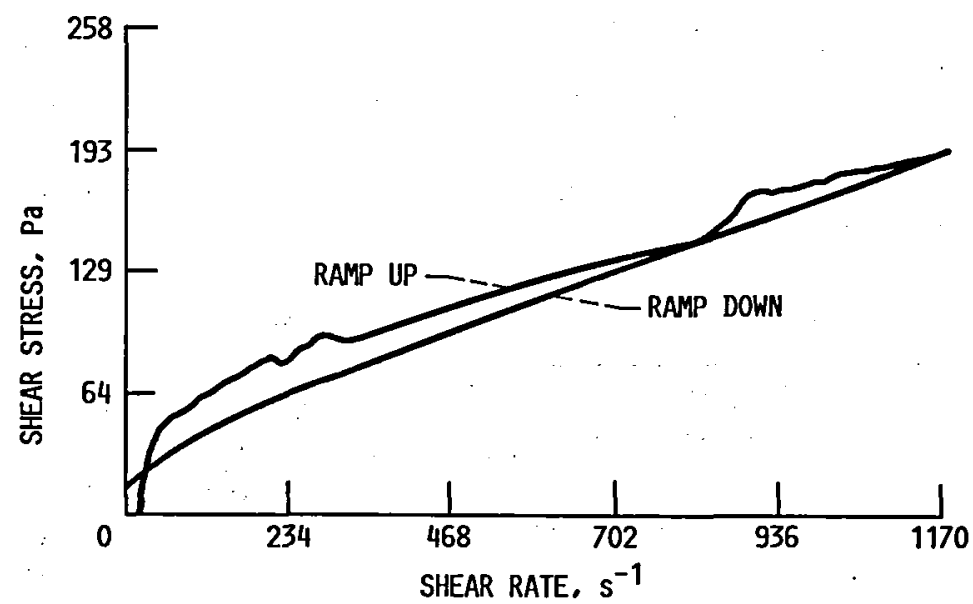

(b) OCTOBER 1987 MAXIMUM SHEAR RATE FLOW CURVE; HAAKE ROTOVISCO RV100, M500 SYSTEM, MV-1 SENSOR SYSTEM.

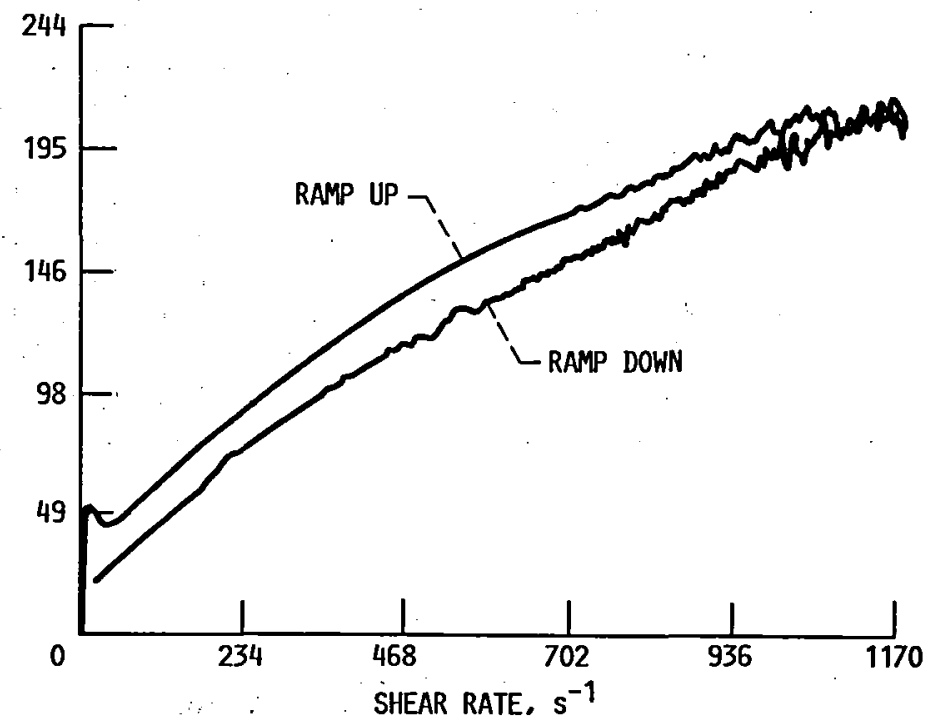

(c) APRIL 1988 MAXIMUM SHEAR RATE FLOW CURVE: HAAKE ROTOVISCO RV100, M500 SYSTEM, MV-HEL SENSOR SYSTEM.

FIGURE 6. - 16 MICRON, 60 wT \%, Al/RP-1 GEL PROPELLANT. 


\begin{tabular}{|c|c|c|c|c|}
\hline \multicolumn{5}{|l|}{$\prod_{\substack{\text { National Aeronautics and } \\
\text { Space Administration }}}$} \\
\hline $\begin{array}{ll}\text { 1. Report No. } & \text { NASA TM-100951 } \\
& \text { AIAA-88-2821 }\end{array}$ & \multicolumn{2}{|c|}{ 2. Government Accession No. } & \multicolumn{2}{|c|}{ 3. Recipient's Catalog No. } \\
\hline \multirow{2}{*}{\multicolumn{3}{|c|}{$\begin{array}{l}\text { 4. Title and Subtitle } \\
\text { Characterization of Aluminum/RP-1 } \\
\text { Gei Propellant Properties }\end{array}$}} & \multicolumn{2}{|l|}{ 5. Report Date } \\
\hline & & & \multicolumn{2}{|c|}{ 6. Performing Organization Code } \\
\hline \multirow{2}{*}{\multicolumn{3}{|c|}{$\begin{array}{l}\text { 7. Author(s) } \\
\text { Douglas C. Rapp and Robert L. Zurawski }\end{array}$}} & \multicolumn{2}{|c|}{$\begin{array}{l}\text { 8. Performing Organization Report No. } \\
\text { E-4242 }\end{array}$} \\
\hline & & & \multicolumn{2}{|c|}{$\begin{array}{l}\text { 10. Work Unit No. } \\
506-42-11\end{array}$} \\
\hline \multicolumn{3}{|l|}{ 9. Performing Organization Name and Address } & \multirow{2}{*}{\multicolumn{2}{|c|}{\begin{tabular}{|l} 
11. Contract or Grant No. \\
\end{tabular}}} \\
\hline \multirow{2}{*}{\multicolumn{3}{|c|}{$\begin{array}{l}\text { National Aeronautics and Space Administration } \\
\text { Lewis Research Center } \\
\text { Cleveland, Ohio } 44135-3191\end{array}$}} & & \\
\hline & & & \multirow{2}{*}{\multicolumn{2}{|c|}{$\begin{array}{l}\text { 13. Type of Report and Period Covered } \\
\text { Technical Memorandum }\end{array}$}} \\
\hline \multicolumn{3}{|c|}{ 12. Sponsoring Agency Name and Address } & & \\
\hline \multicolumn{3}{|c|}{$\begin{array}{l}\text { National Aeronautics and Space Administration } \\
\text { Washington, D.C. } 20546-0001\end{array}$} & \multicolumn{2}{|c|}{ 14. Sponsoring Agency Code } \\
\hline \multicolumn{5}{|l|}{ 15. Supplementary Notes } \\
\hline \multicolumn{5}{|c|}{$\begin{array}{l}\text { Prepared for the } 24 \text { th Joint Propulsion Conference cosponsored by the AIAA, } \\
\text { ASME, SAE, and ASEE, Boston, Massachusetts, July 11-13, 1988. Douglas C. Rapp, } \\
\text { Sverdrup Technology, Inc. NASA Lewis Research Center Group, Cleveland, Ohio } \\
\text { 44135; Robert L. Zurawski; NASA Lewis Research Center. }\end{array}$} \\
\hline \multicolumn{5}{|l|}{ 16. Abstract } \\
\hline \multicolumn{5}{|c|}{$\begin{array}{l}\text { Research efforts are being conducted by the NASA Lewis Research Center to formu- } \\
\text { late and characterize the properties of Al/RP-l and RP-l gelled propellants for } \\
\text { rocket propulsion systems. Twenty four different compositions of gelled fuels } \\
\text { have been formulated with } 5 \text { and } 16 \mu \mathrm{m} \text {, atomized aluminum powder in RP-1. The } \\
\text { total solids concentration in the propellant varied from } 5 \text { to } 60 \text { wt } \% \text {. Tests } \\
\text { were conducted to evaluate the stability and rheological characteristics of the } \\
\text { fuels. Physical separation of the solids occurred in fuels with less than } \\
50 \text { wt } \% \text { solids concentration. The rheological characteristics of the Al/RP-1 } \\
\text { fuels varied with solids concentration. Both thixotropic and rheopectic gel } \\
\text { behavior were observed. The unmetallized RP-l gels, which were formulated by a } \\
\text { different technique than the Al/RP-l gels, were highly viscoelastic. A history } \\
\text { of research efforts which have been conducted to formulate and characterize the } \\
\text { properties of metallized propellants for various applications is also given. }\end{array}$} \\
\hline \multicolumn{2}{|c|}{$\begin{array}{l}\text { 17. Key Words (Suggested by Author(s)) } \\
\text { Metallized propelfants; Aluminum; } \\
\text { RP-1; Gelled propellants; } \\
\text { Rocket propellants; Rheological } \\
\text { properties; Tripropellants. }\end{array}$} & \multicolumn{3}{|c|}{$\begin{array}{l}\text { 18. Distribution Statoment } \\
\text { Unclassified - Unlimited } \\
\text { Subject Category } 28\end{array}$} \\
\hline $\begin{array}{l}\text { 19. Security Classif. (of this report) } \\
\text { Unclas s i fied }\end{array}$ & \multicolumn{2}{|c|}{$\begin{array}{l}\text { o. Security Classif. (of this page) } \\
\text { Unclass if i e }\end{array}$} & $\begin{array}{c}\text { 21. No of pages } \\
22\end{array}$ & $\begin{array}{r}\text { 22. } \text { Price* } \\
\mathrm{AO2}\end{array}$ \\
\hline
\end{tabular}


National Aeronautics and

Space Administration

Lewis Research Center

Cleveland, Ohio 44135

Official Business

Penalty for Private Use $\$ 300$

\section{FOURTH CLASS MAIL}

\section{ADDRESS CORRECTION REQUESTED}

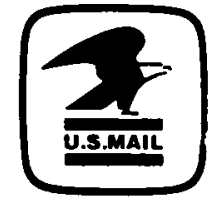

Postage and Fees Pard Natıonal Aeronautics and

Space Administration

NASA.451 